\title{
Correction to: Dynamic expression of homeostatic ion channels in differentiated cortical astrocytes in vitro
}

\author{
Francesco Formaggio ${ }^{1} \cdot$ Martina Fazzina $^{1,2} \cdot$ Raúl Estévez $^{3,4} \cdot$ Marco Caprini $^{1} \cdot$ Stefano Ferroni $^{1}$
}

Published online: 3 December 2021

(c) The Author(s) 2021

\section{Correction to: Pflügers Archiv - European Journal of Physiology \\ https://doi.org/10.1007/s00424-021-02627-x}

Originally, the article was published online with errors that do not reflect the content of the accepted manuscript. One table is missing (table 2), the table 2 should be table 3 and the citations of the tables and figures in the main text are not correct as there is a shift in association of all tables and figures 1-7.

The original article has been corrected.

Publisher's note Springer Nature remains neutral with regard to jurisdictional claims in published maps and institutional affiliations.

The online version of the original article can be found at https:// doi.org/10.1007/s00424-021-02627-x

Stefano Ferroni

stefano.ferroni@unibo.it

1 Department of Pharmacy and Biotechnology, University of Bologna, Via San Donato 19/2, 40127 Bologna, Italy

2 Present Address: Department for Life Quality Studies, University of Bologna, Rimini, Italy

3 Departament de Ciències Fisiològiques, IDIBELL-Institute of Neurosciences, Universitat de Barcelona, Barcelona, Spain

4 Centro de Investigación Biomédica en Red Sobre

Enfermedades Raras (CIBERER), Instituto de Salud Carlos

III, Madrid, Spain 